\title{
ESTUDO DO SISTEMA RADICULAR DO ARROZ
}

Emílio B. Germek, engenheiro agrónomo, Seç̧ão de Genética; Romeu Inforzato e Coaraci M. Franco, engenheiros agrônomos, Seçãa de Fisiologia e Alimentafãa de Plantas, Instituto Agronômico de Campinas

\section{1-INTRODUÇÃO}

O estudo da distribuição do sistema radicular das nossas principais plantas econômicas é de grande interêsse, por trazer preciosas e úteis informações que poderão ser aplicadas à melhoria dos métodos de plantio, ora em voga, para essas diferentes culturas. Esse o motivo por que investigações dessa natureza foram já efetuadas no Instituto Agronômico de Campinas, com referência à distribuição do sistema radicular do café e do guandu, tendo sido desenvolvida uma técnica especial, simples e eficiente, aplicável a êsses estudos (1).

O cultivo do arroz (Oriza sativa L.), no Estado de São Paulo, vem aumentando de importância nestes últimos anos. Em 1949, foi cultivada uma área aproximada de $543000 \mathrm{ha}$, cuja produção se avalia em cêrca de. 758300 toneladas de arroz em casca.

Duas modalidades bem distintas de cultura dêsse cereal podem ser encontradas nas diversas regioes que o cultivam em São Paulo. Uma delas é feita com irrigação e a outra em terrenos sem irrigação. Esta última; denominada "cultura de sequeiro", é mais importante, pois é por seu meio que se obtém a maior parte do arroz produzido no Estado.

As diversas experiências de variedades, realizadas pelo Instituto Agronômico de Campinas, têm indicado que há visíveis diferenças no comportamento das principais variedades quanto à produção, sob êsses dois regimes de cultivo (2). Assim, para a cultura de sequeiro, as variedades Pérola e Iguape-catete são as mais recomendáveis; as variedades Dourado-agulha e Iguape-agulha são de mediana produção, e a variedade Fortuna apresenta sempre produções muito reduzidas. Esta última, no entanto, é das mais produtivas em culturas irrigadas.

Essa especialização de variedades para diferentes condições de cultivo pode estar correlacionada com a distribuição de seu sistema radicular. Com o fim de averiguar essas possiviveis diferenças é que realizamos o presente estudo. As observaçóes feitas podem, também, servir para orientar algumas práticas culturais, tais como preparo do solo, adubaçôes, espaçamento, etc.

\section{2-MATERIAL E METODO}

As cinco variedades atrás mencionadas foram usadas para êstes estudos, a saber: Pérola, Iguape-catete, Fortuna, Dourado-agulha e Iguape-agulha. Tôdas essas variedades produzem bem em cultura irrigada. A sua diferen- 
ciação se dá quando estão sujeitas a períodos de sêca, como é comum em cultura de sequeiro, quando se sobressaem as variedades Pérola e Iguapecatete.

As variedades foram semeadas em terreno sem irrigação, em linhas, espaçadas de um metro, empregando-se três gramas de sementes por metro de sulco, em filête contínuo. A semeação foi executada em 19 de novembro de 1946, iniciando-se o estudo em 14 de abril de 1947, quando as plantas estavam com cinco meses de idade, aproximadamente, e já maduras. A plantação foi feita em solo tipo terra roxa misturada, da Estação Experimental Central do Instituto Agronômico, em Campinas. O preparo dêsse solo e os tratos culturais foram os normais para a cultura de sequeiro.

$O$ estudo do sistema radicular foi realizado em dois sentidos : ao longo da linha de plantação e transversalmente a ela.

Adaptamos ao arroz a técnica empregada para o estudo do sistema radicular do cafeeiro por Franco e Inforzato (1).

Para o estudo da distribuição do sistema radicular, ao longo da linha, procedeu-se da seguinte maneira : abriu-se uma cova de um metro de comprimento, de modo que uma das paredes ficasse a 12,5 centímetros do centro da linha. Essa parede foi inteiramente desmanchada em blocos de $20 \times 25$ cm de base e a profundidades variáveis, sendo nas três camadas mais superficiais de $5 \mathrm{~cm}$, nas duas seguintes de $10 \mathrm{~cm}$ e, nas restantes, de $20 \mathrm{~cm}$. $O$ lado de $25 \mathrm{~cm}$ era perpendicular à linha de plantas, ficando estas exatamente situadas na linha mediana dos blocos. Juntamente com os blocos foram, portanto, retiradas tôdas as raízes existentes no bloco de terra compreendido entre $12,5 \mathrm{~cm}$ de cada lado da linha.

No estudo no sentido perpendicular às linhas, foi aberta uma cova neste sentido abrangendo as cinco linhas, uma de cada variedade. As dimensóes dos blocos de terra retirados foram as mesmas que para o estudo ao longo da linha.

As raízes de cada bloco foram desembaraçadas da terra aderente, lavadas, sêcas ao ar e depois pesadas. Em seguida, sôbre um pano prêto, onde estavam representados em tamanho natural os perfis dos blocos retirados do solo, distribuímos as raízes, de tal maneira que reconstituíssem a distribuição originalmente existente no solo, ocupando as raízes o retângulo correspondente ao bloco de onde provieram. Este arranjo foi, a seguir, fotografado.

\section{3-DISCUSSÃO DOS RESULTADOS OBTIDOS}

No quadro 1 apresentamos os pesos das raízes encontradas nas diferentes camadas do solo, no sentido da linha, compreendendo a extensão de um metro, numa faixa de $25 \mathrm{~cm}$ de largura.

Examinando-se o quadro 1, pode-se notar que mais de duas têrças partes do sistema radicular do arroz, em qualquer das variedades aqui estudadas, se encontram nos primeiros $5 \mathrm{~cm}$ da camada mais superficial do' solo. Até $15 \mathrm{~cm}$, profundidade correspondente mais ou menos à camada arável 
Quadro 1.-Pêso de raízes encontradas a diversas profundidades, e percentagens em relação ao pêso total das raízes, das cinco variedades de arroz em estudo

\begin{tabular}{|c|c|c|c|c|c|c|c|c|c|c|}
\hline \multirow{2}{*}{$\begin{array}{l}\text { Profundi- } \\
\text { dade das } \\
\text { camadas } \\
\text { (em centi- } \\
\text { metros) }\end{array}$} & \multicolumn{2}{|c|}{ Pérola } & \multicolumn{2}{|c|}{ Iguape-catete } & \multicolumn{2}{|c|}{ Fortuna } & \multicolumn{2}{|c|}{$\begin{array}{l}\text { Dourado- } \\
\text { agulha }\end{array}$} & \multicolumn{2}{|c|}{ Iguape-agulha } \\
\hline & pêso & $\begin{array}{c}\text { per- } \\
\text { centa- } \\
\text { gem }\end{array}$ & pêso & $\begin{array}{c}\text { per- } \\
\text { centa- } \\
\text { gem }\end{array}$ & pêso & $\begin{array}{l}\text { per- } \\
\text { centa- } \\
\text { gem }\end{array}$ & pêso & \begin{tabular}{|c|} 
per- \\
centa- \\
gem
\end{tabular} & péso & $\begin{array}{c}\text { per- } \\
\text { centa- } \\
\text { gem }\end{array}$ \\
\hline & $g r$ & & $g r$ & & $g r$ & & $g r$ & & $g r$ & \\
\hline 0 a & 65,061 & 66,11 & 87,850 & 72,09 & 70,089 & 71,95 & 76,016 & 79,05 & 69,968 & 79,94 \\
\hline 5 \& 10 & 23,828 & 24,21 & 16,840 & 13,82 & 16,640 & 17,08 & 12,230 & 12,71 & 12,244 & 13,98 \\
\hline 10 a 15 & 5,747 & 5,84 & 7,259 & 5,95 & 5,970 & 6,13 & $\mathbf{3 , 6 1 2}$ & 3,75 & 2,245 & 2,56 \\
\hline 15 a 25 & 1,422 & 1,44 & 2,588 & 2,12 & 2,187 & 2,24 & 0,935 & 0,97 & 0,818 & 0,93 \\
\hline 25 a 35 & 0,865 & 0,87 & 2,210 & 1,81 & 1,001 & 1,02 & 1,042 & 1,08 & 0,510 & 0,58 \\
\hline 35 a & 0,640 & 0,65 & 2,260 & 1,85 & 0,650 & 0,66 & 1,313 & 1,36 & 0,781 & 0,89 \\
\hline 55 a & 0,360 & 0,36 & 1,810 & 1,48 & 0,420 & 0,43 & 0,469 & 0,48 & 0,380 & 0,43 \\
\hline 75 a 95 & 0,245 & 0,25 & 0,650 & 0,53 & 0,300 & 0,30 & 0,320 & 0,33 & 0,290 & 0,33 \\
\hline 95 a 115 & 0,218 & 0,22 & 0,335 & 0,27 & 0,106 & 0,11 & 0,113 & 0,11 & 0,193 & 0,22 \\
\hline 115 a 135 & 0,0 & 0,02 & 56 & 0,04 & 0,046 & 0,04 & 0,106 & 0,11 & 0,095 & 0,10 \\
\hline Total. & 98,406 & & 121,858 & & 97,409 & & 96,156 & & 87,544 & \\
\hline
\end{tabular}

do solo, mais de $95 \%$ do total de pêso das raízes são aí encontrados. Neste particular, faz exceção a variedade Iguape-catete, que apresenta uma distribuição do sistema radicular ligeiramente mais profunda. Esta mesma variedade é a que possui o sistema radicular mais abundante.

Pelo exame das estampas 1 a 5 , correspondentes aos cortes longitudinais, e da estampa 6, correspondente ao corte transversal, pode-se ter uma visão mais nítida do que é a distribuição do sistema radicular do arroz. Por elas também se pode ver que, de fato, a maior parte das raízes se encontram nos primeiros $15 \mathrm{~cm}$ da camada mais superficial do solo.

Notou-se que, de modo geral, o sistema radicular não atinge eficientemente mais do que um metro de profundidade, sendo o limite máximo de 135 centímetros. $\mathrm{Na}$ variedade Iguape-catete, no entanto, maior quantidade de raízes vai mais profundamente.

Sendo o sistema radicular do arroz assim tão superficial, tem-se al uma explicação para o fato, comumente observado, do dano que as ervas más causam à planta do arroz, devido à intensa concorrência que exercem. Daí serem indicados para o cultivo do arroz terrenos não infestados de ervas más, preconizando-se, também, o bom preparo do solo. Encontrando-se as raízes do arroz, em quase sua totalidade, na camada arável do solo, é lícito deduzir que araçōes profundas levarão o sistema radicular a se aprofundar, ficando, à disposição da planta, camadas antes não exploradas eficientemente. As araç⿸丆es profundas serão talvez as mais indicadas. $O$ terreno deve ser mantido limpo com capinas repetidas e bem superficiais, para atingir as ervas más ainda pequenas e não cortar as raízes do arroz que se encontram próximo à superfície do solo. 
As pequenas diferenças obscrvadas no sistema radicular entre as diversas variedades examinadas não são de molde a poder-se tirar conclusões sôbre as causas da especialização das variedades para a cultura de sequeiro.

\section{4-RESUMO E CONCLUSÕES}

Estudamos a distribuição do sistema radicular do arroz em dois sentidos, ao longo da linha de plantação e transversalmente a ela, de cinco variedades, em cultura de sequeiro. Foram retirados prismas de terra, de dimensões definidas, e, com as raízes aí encontradas, reconstituiu-se a sua distribuição no solo.

Da observação dos resultados, chega-se às seguintes conclusões, para as variedades e condições estudadas:

1) O sistema radicular do arroz é muito superficial, sendo que duas têrças partes se encontram nos primeiros $5 \mathrm{~cm}$ da camada mais superficial do solo. $\Lambda$ té $15 \mathrm{~cm}$, que corresponde à camada arável, com exceção da variedade Iguape-catete que apresenta uma distribuição ligeiramente mais profunda, mais de $95 \%$ do total em pêso de raízes são encontrados nesta camada.

2) Não se conseguiu chegar a uma conclusão definitiva, quanto a scr o aprofundamento do sistema radicular do arroz o principal fator determinante da especialização das variedades para a cultura de sequeiro.

3) O reconhecimento do fato de que o sistema radicular da planta de arroz está localizado, na sua maior parte, na camada arável do solo, sugere que é desejável uma aração profunda antes do plantio e capinas frequentes e bem superficiais durante a cultura, para eliminar a competição das ervas más.

\section{SUMMARY}

The development of the root system on five varieties of rice grown under upland conditions, has been studied. It has been found, with the rice varieties used and under the conditions tested, that 66 percent of the roots occured within 5 centimeters and 95 percent within 15 centimeters of the surface of the ground. $\mathbf{A}$ few roots were found to reach a depth of 1 meter, and occasionally to a depth of 1.35 meter.

The Iguape-catete variety of rice showed a tendency to develop a somewhat deeper root system than the other varieties studied.

Recognition of the fact that development of the roots of the rice plant is largely within the plowed layer of soil, suggests that deep plowing prior to planting with frequent and shallow cultivation following planting, to eliminate weed competition, would be desirable.

\section{LITERA'TURA CITADA}

1. Franco, C. M. e R. Inforzato. O sistema radicular do cafeeiro nos principais tipos de solo do Estado de São Paulo. Bragantia 6: 443-458. 1946.

2. Germek, E: Métodos de cultura e variedades de arroz. Revista de Agricultura de Piracicaba 21: 264-270. 1946. 


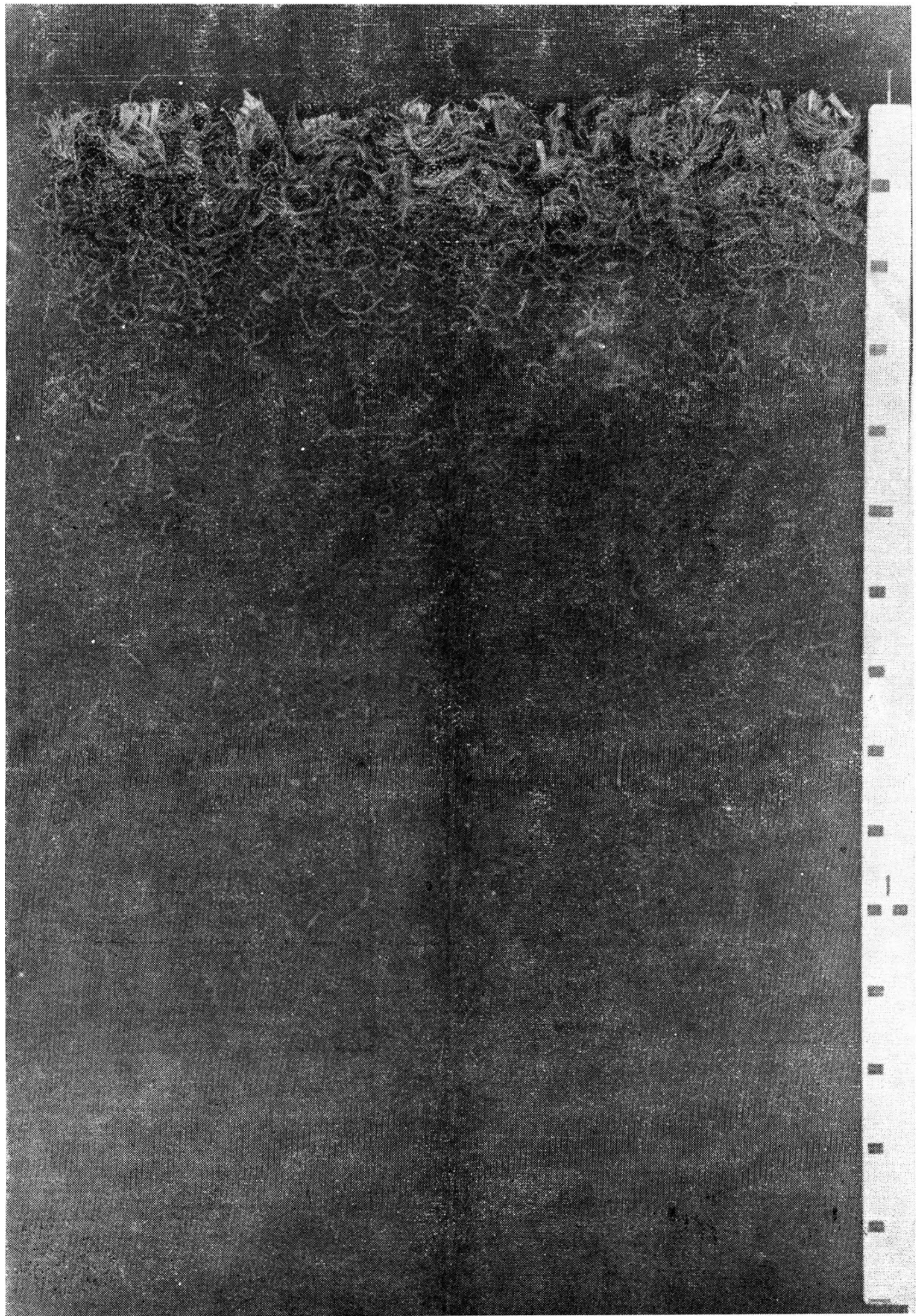

Distribuiçäo do sistema radicular do arroz, da variedade Pérola, ao longo da linha. 


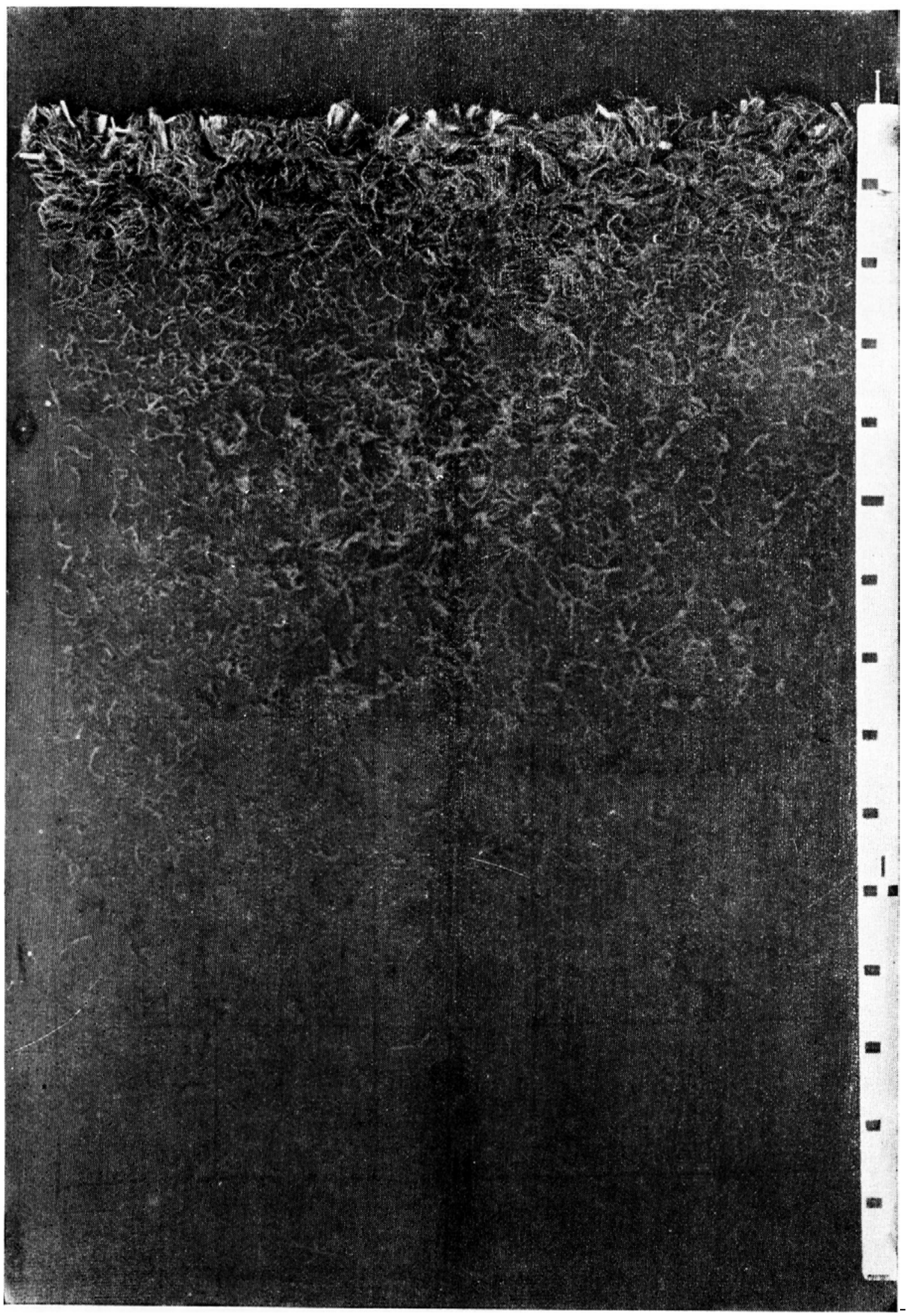

Distribuiçăo do sistema radicular do arroz, da variedade Iguape-catete, ao longo da linha. 


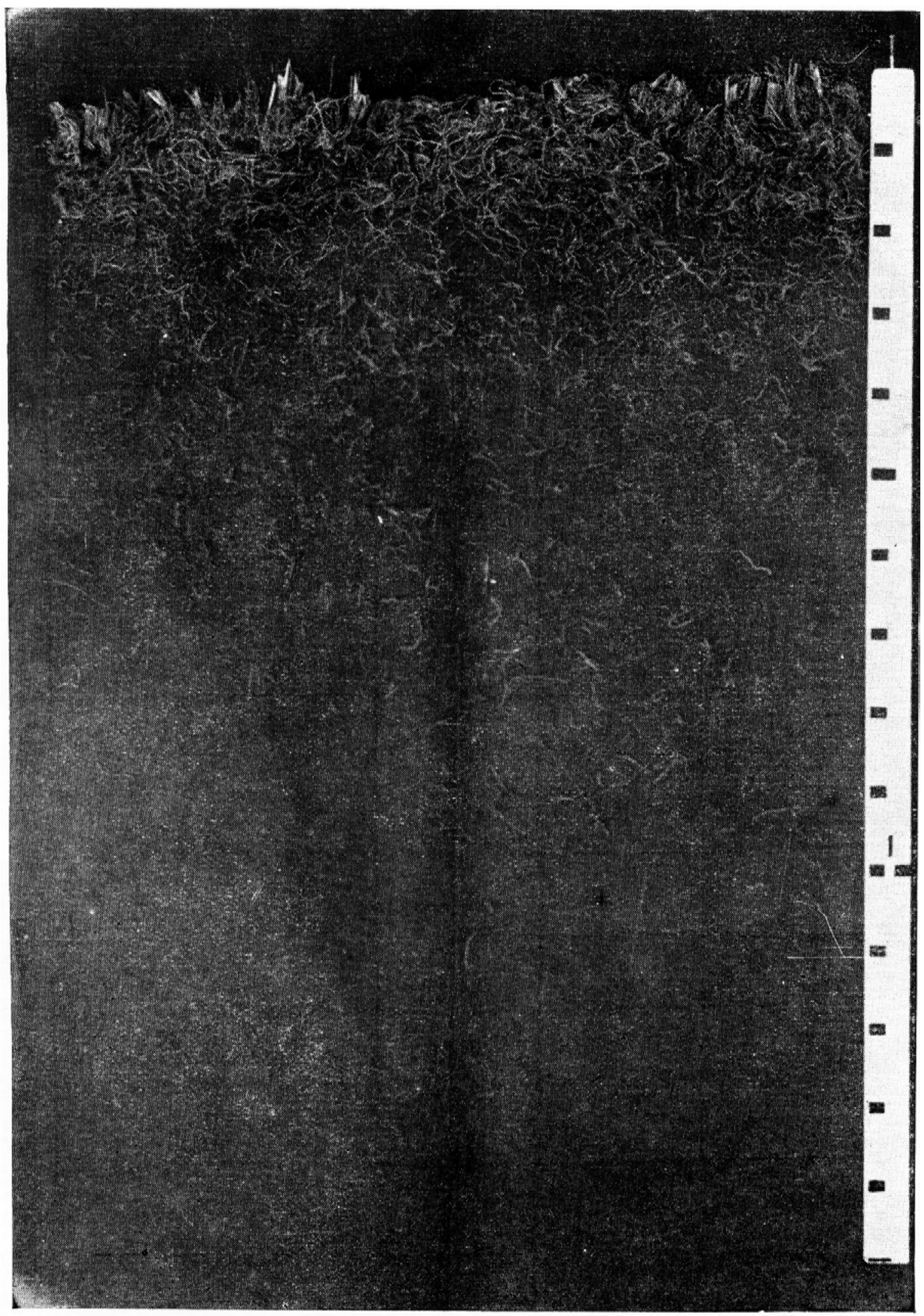

Distribuição do sistema radicular do arroz, da variedade Fortuna, ao longo da linha. 


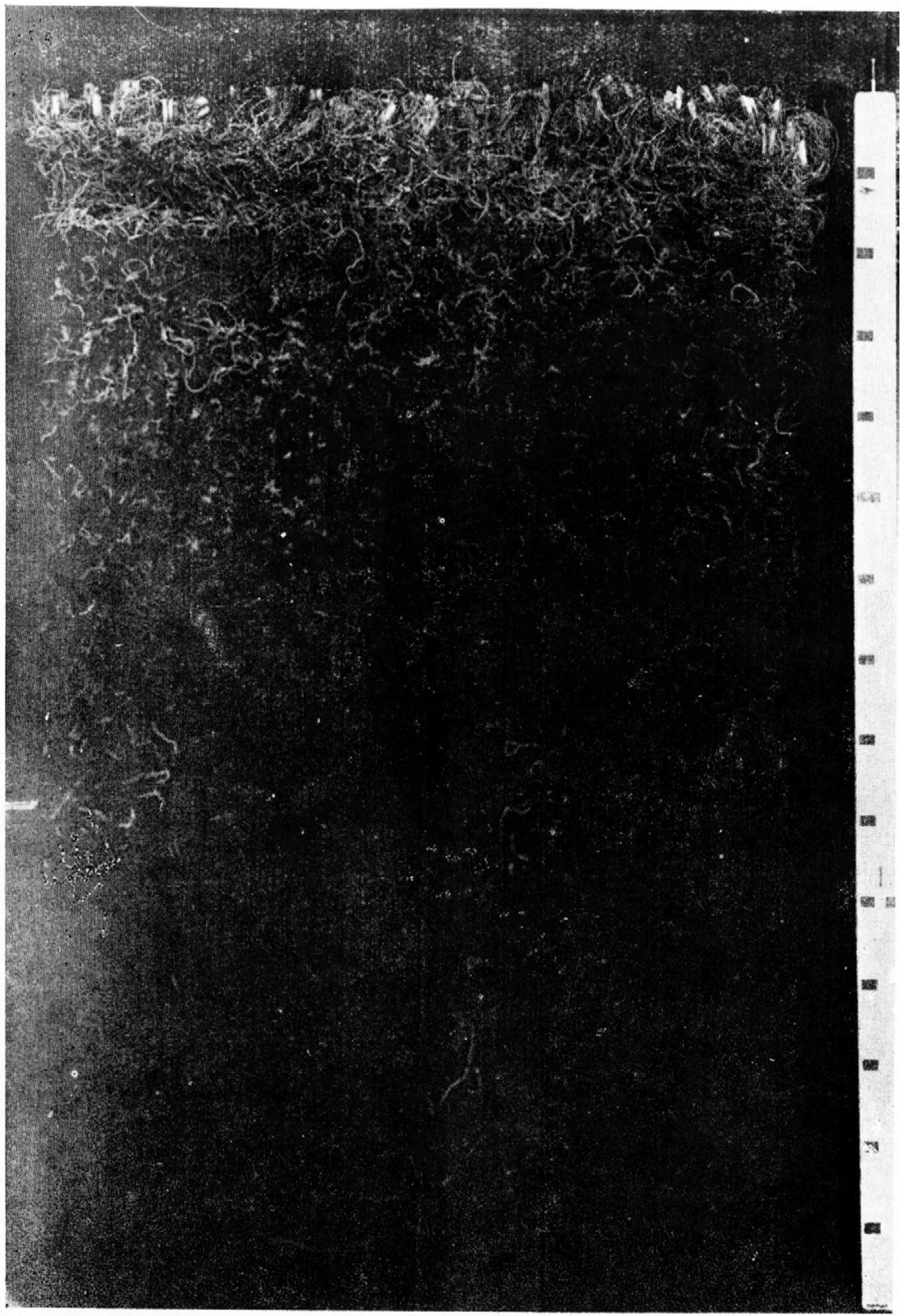

Distribuição do sistema radicular do arroz, da variedade Dourado-agulha, ao longo da linha. 


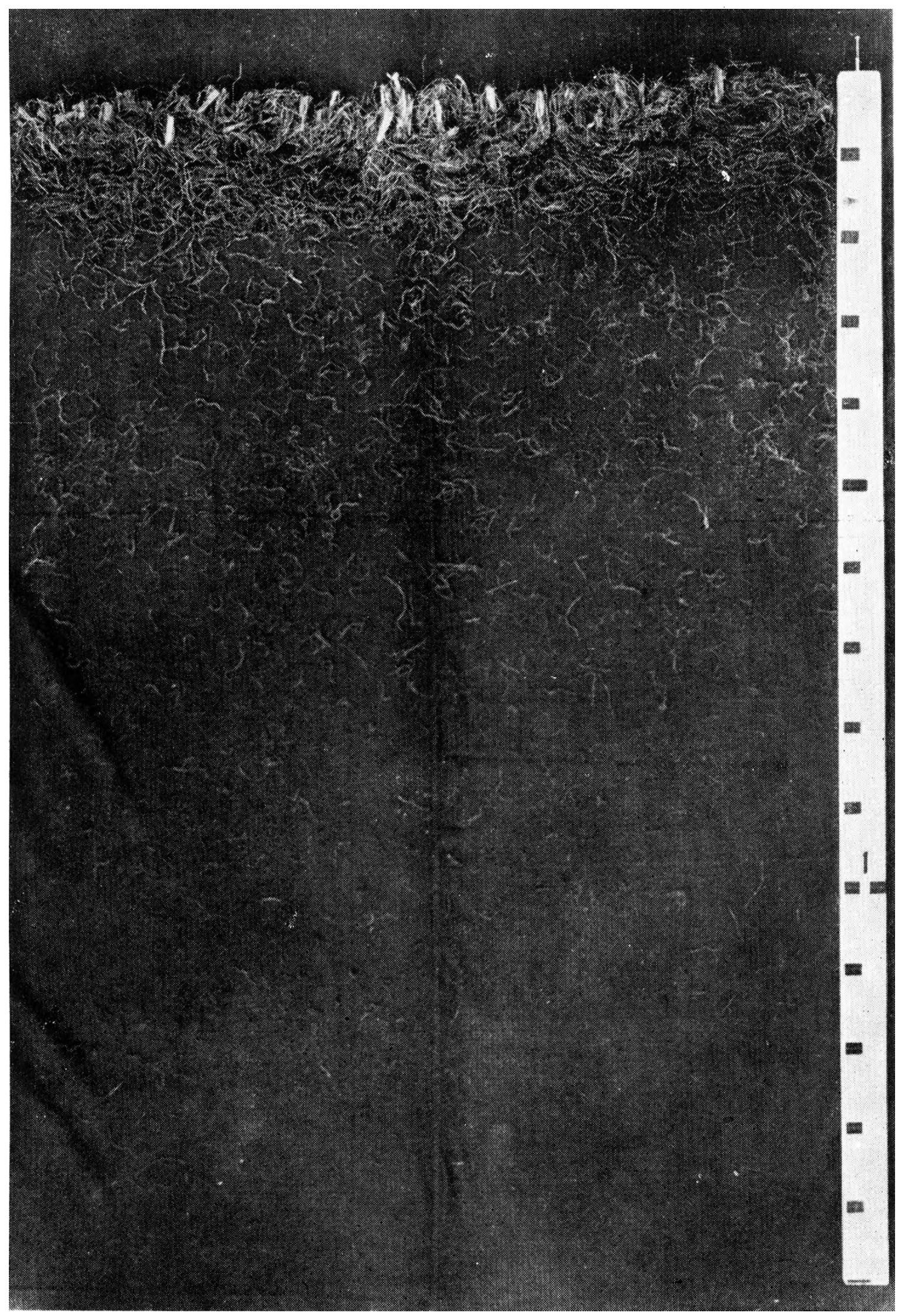

Distribuiçăo do sistema radicular do arroz, da variedade Iguape-agulha, to longo da linha. 


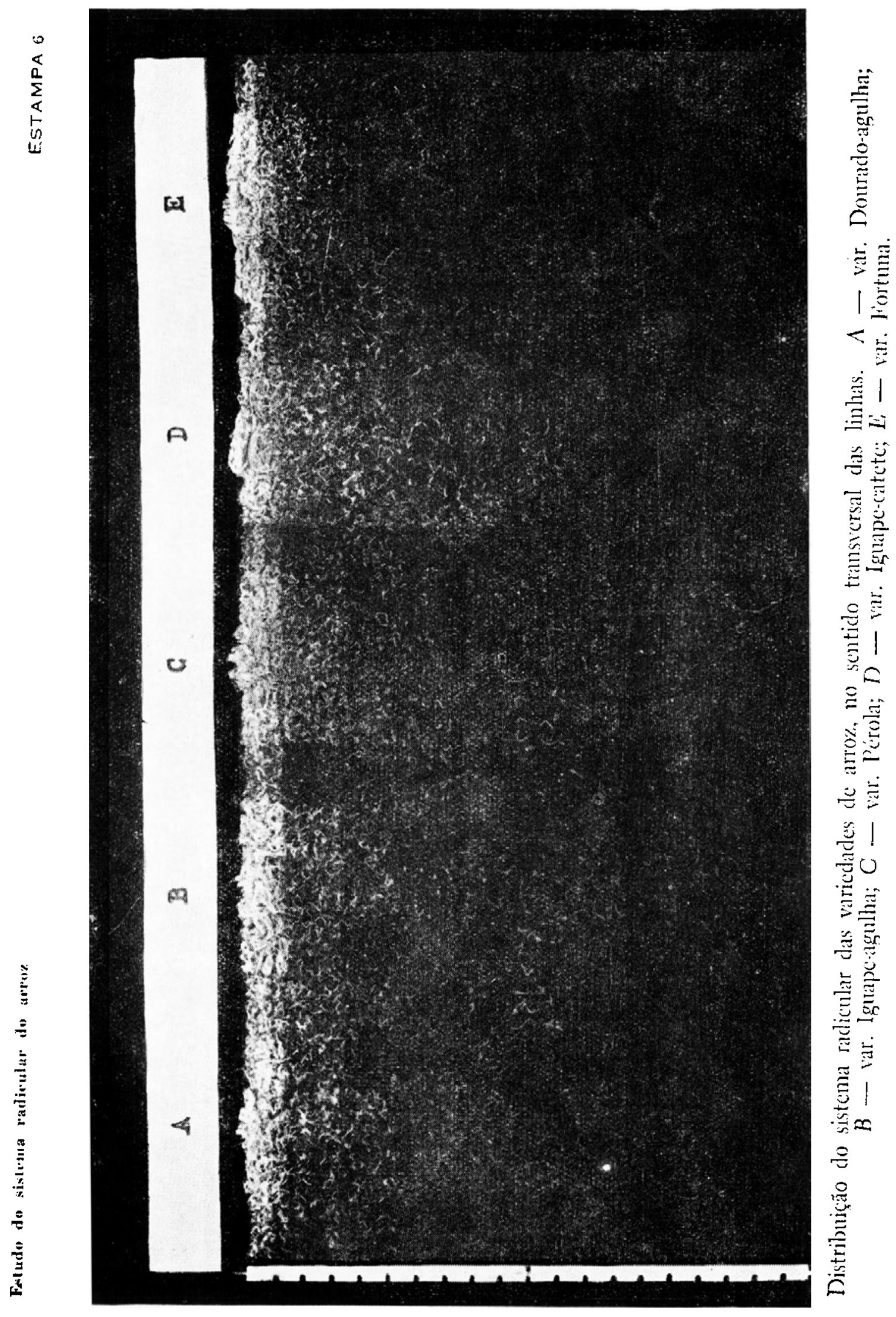

